\title{
Carnets
}

Revue électronique d'études françaises de l'APEF

Première Série - 1 Numéro Spécial | 2009

Cultures littéraires : nouvelles performances \& développement

\section{O Ensaio: uma visão crítica da cultura pelo traço literário}

\section{André Manuel Ruivo Senos Matias}

\author{
(2) OpenEdition \\ Journals \\ Edição electrónica \\ URL: http://journals.openedition.org/carnets/3567 \\ DOI: $10.4000 /$ carnets.3567 \\ ISSN: 1646-7698 \\ Editora \\ APEF \\ Edição impressa \\ Data de publição: 1 Junho 2009 \\ Paginação: 91-103
}

\section{Refêrencia eletrónica}

André Manuel Ruivo Senos Matias, « O Ensaio: uma visão crítica da cultura pelo traço literário », Carnets [Online], Première Série - 1 Numéro Spécial | 2009, posto online no dia 16 junho 2018, consultado o 19 abril 2019. URL : http://journals.openedition.org/carnets/3567 ; DOI : 10.4000/ carnets.3567

Carnets est mis à disposition selon les termes de la licence Creative Commons - Atribution - Pas d'utilisation commerciale 4.0 International. 


\title{
O ENSAIO: UMA VISÃo CRÍTICA DA CULTURA PELO TRAÇO LITERÁRIO
}

\author{
ANDRÉ MANuel Ruivo Senos Matias \\ Universidade de Aveiro \\ amatias@ua.pt
}

\begin{abstract}
Resumo
Aspiramos abordar o conceito de "cultura literária", perspectivando-o não apenas num prisma de aquisição de uma dada memória literária, mas encarando também cultura literária e a própria literatura como uma capacidade de Weltanschauung. Sublinhar-se-á a competência criativa da literatura, enquanto promotora de uma leitura crítico-interpretativa da sociedade, em que o escritor e o leitor estão circunstanciados. Observaremos a literatura como um espaço de criação, seja ela construção imagética ou reflexão sobre o mundo que nos pertence.

O ensaio é motor de polémica social que visa uma acção efectiva, sendo por isso uma mais-valia o facto de ter uma perspectiva tripartida da realidade. Ciência, Filosofia e Literatura em osmose permitem-Ihe artisticamente interferir e intervir na realidade humana. Como tal, o ensaio é uma literacia de vida, permitindo interpretá-la e modificá-la.
\end{abstract}

\begin{abstract}
We aim at exploring the concept of 'literary culture', not only seeing it as an acquisition of a given literary memory, but also understanding literary culture and literature itself as Weltanschauung. We will emphasize the creative competence of literature whilst promoter of a critic-interpretative analysis of a society in which the author and the reader are circumstantiated. We will conceive literature as a space of creation, either being an imagetic construction or a reflexion about our world. Thus we aspire at emphasizing the interventive power of literature in society, taking the essay as an example.

The essay is a force of social polemics that aims at an effective action, with the advantage of having a three-fold perspective of reality. Science, Philosophy and Literature in osmosis allow the essay to artistically interfere and to intervene in human reality. As a consequence, the essay is a life literacy that allows to interpret and to modify it.
\end{abstract}

Palavras-chave: Ensaísmo, Cultura literária, Crítica, Blogosfera

Keywords: Essayism, Literary culture, Critic, Blogosphere

André Manuel Ruivo Senos Matias, "O Ensaio: uma visão crítica da cultura pelo traço literário”, Carnets, Cultures littéraires: nouvelles performances et développement, nº spécial, automne / hiver 2009, pp. 91-103. 
La science est grossière, la vie est subtile, et c'est pour corriger cette distance que la littérature nous importe.

Roland Barthes, Leçon [Inaugural Lecture at the Collège de France], Paris 1978

O tempo coevo matiza-se por uma sociedade que cada vez mais se sente prisioneira e dependente de um domínio por parte de uma tecnologia, que tem desaguado numa certa depauperação e não menos agonizante depreciação das humanidades, das artes e da cultura. Não seria tão preocupante o cenário se a concepção dessa técnica imperante mantivesse as suas bases fundacionais, presentes ainda na sua carga etimológica'. Contudo, hodiernamente, técnica já não é um sinónimo directo de arte. Falamos de arte não apenas no sentido mais usual do termo, mas também com a amplitude necessária para nela conter a sabedoria do artífice que zelosamente desempenha a sua profissão. É com a vontade de voltar a encontrar esses artesãos, arautos ainda de uma arte vital, que nos propomos perscrutar pelas sinuosidades de uma matéria tão palúdica mas simultaneamente tão aliciante: o ensaio como utensílio e modo para interpretar literariamente a cultura.

Antes de abordarmos verdadeiramente o nosso objecto de estudo, é jussivo que se apontem algumas directrizes conceptuais, balizando os campos que a partir deste momento passaremos a atravessar. O Homem, desde sempre, tem tentado encontrar o seu lugar no mundo, servindo-se para isso de várias ferramentas, sejam elas empíricas ou conceptuais. Não interessando agora encontrar ou classificar esse tipo de instrumentos, cremos que será de aceitação geral que o Homem ao se observar no mundo, o seu lugar no mundo, se vai sentindo inquietado e curioso. Essa preocupação tornou-se gradualmente fonte de pensamento e de meditação. Desta feita, é neste contexto que se vai desenvolvendo o conceito de cultura. Urge, pois, responder a uma questão que se levanta: o que é a cultura e mais concretamente o que poderá ser encarado como cultura literária. Por cultura, numa acepção simples mas que permite obter da sua etimologia o verdadeiro significado, entendemos um aglomerado de práticas e acções que seguem um dado padrão no espaço e no tempo. Este tipo de práticas poderá incluir crenças, comportamentos e valores, que de um modo específico dão corpo a uma dada sociedade, conferindo-Ihe unidade, identidade e especificidade durante um período temporal particular. Por outro lado, falamos também de cultura quando nos referimos à criação de valores de um dado grupo de pessoas, nas normas que elas seguem, bem como nos bens materiais que criam.

De um modo geral, cultura é criação: porque é recebida dos ancestrais, porque vai sendo criada e modificada nos seus pontos de vista, facto que desemboca numa contínua renovação e revitalização cultural. É neste particular que melhor se entende a necessidade

\footnotetext{
${ }^{1}$ A este respeito, relembramos o significado e a abrangência da palavra helénica techné. 
de analisar neste contexto a cultura sob um prisma sócio-filosófico, ainda que privilegiaremos mais a observação filosófica. Assim, podemos afiançar que cultura poderá passar por um agrupado de manifestações humanas, que contrastam com um comportamento natural, tendo como objectivo satisfazer as necessidades e ambições do Homem. Se, por um lado, cultura é simultaneamente um conjunto de conhecimentos teóricos e práticos que se apre(e)nde e transmite aos de hoje e aos de um amanhã, por outro, também não deixa de ser a consequência do modo como diacronicamente certos grupos foram resolvendo as suas dificuldades. Em suma, tal como referiu María Zambrano, cultura é a realização ou até mesmo o fracasso de um modo de se ser homem (cf. Zambrano, 2004: 157) - independentemente da maneira que for, dado que ele é um ser mutável e de transformação.

Não obstante, os contornos do conceito cultura particularizam-se, quando dentro dele lidamos especificamente com a concepção de cultura literária. Não será tão profícuo definir este conceito lato sensu, se não o comentarmos no contexto particular do ensaio. Analisando não a noção de cultura literária em si, mas o adjectivo literário, retenhamos toda a carga simbólica e semântica que alberga. De origem latina, oriundo de litterarius, a, um significando "relativo à leitura e à escrita", este adjectivo tem a sua verdadeira génese no substantivo littera, ae, cujo sentido primeiro é letra, mas que paulatinamente se dilata, albergando também acepções como literatura, cultura, ou erudição. De um modo despretensioso, podemos afirmar que "literário" é tudo aquilo relativo às letras, ou à literatura, sendo também lícito referir que ao literário pertence qualquer espécie de cultura adquirida através do estudo. No entanto, grosso modo, a este adjectivo associam-se com certa naturalidade as belas-letras e por consequência as humanidades.

Todavia, por cultura literária não podemos circunscritamente entender a simples aquisição de conhecimentos e conteúdos na área da literatura. Queremos de um modo claro não nos restringir ao conceito que vulgarmente entende a cultura como a obtenção de conhecimentos e práticas de vida reconhecidas como melhores, superiores, visto que a esta acepção normalmente se associa ao que é também descrito como "alta cultura" (cujo sentido é sectário e de segmentação ${ }^{2}$ ). Estamos convictos de que seja lícito conceber o conceito de "cultura literária" entendendo-o como um processo de constituição de um certo conhecimento "literário" efectivo através da frequentação de obras. Essa cultura literária pressuporá uma certa memória dos textos, mas também prevê o conhecimento da língua em que essas obras estão escritas, bem como a capacidade de encontrar os liames que unem numa intrincada rede as várias obras. Contudo, a "cultura literária" não se esgota nesta significação. Entendendo literatura como Vida e como uma arte de a ver e interpretar,

\footnotetext{
${ }^{2}$ É com alguma frequência que, quando se emprega a palavra cultura no singular, se pretende designar não a diversidade de culturas que existe mas sim a cultura ideal, à qual todos se deverão reger indistintamente.
} 
cremos que também é legítimo perceber a cultura literária como uma análise e construção do mundo que nos rodeia. Ver a cronotopia literariamente, ter a capacidade de decifrar o mundo sob a lupa da literatura é também mais uma das valências da cultura literária.

Por outro lado, poder-se-á entender a noção de cultura literária como uma espécie de amálgama entre as características mais peculiares da literatura e os contornos de outras áreas do saber, nomeadamente as ciências - e dentro delas as ciências humanas. Cientes de que quando falamos em cultura literária isso é por si só a materialização da própria cultura e de um modo singular de a ver e de a reificar, a literatura tem a capacidade de se emaranhar pelos espaços intersticiais que medeiam a própria literatura, a ciência e a filosofia. Temos a consciência de que com a literatura, no contexto de uma cultura literária, o objectivo principal não é uma interpretação do mundo de um modo sistemático, mas sim de uma maneira mais humanizada, seguindo o trilho de uma racionalidade argumentativa, em que o calor do humano e do humanizável se sentem sintomaticamente. Partindo do pressuposto de que cultura é criação, podemos aventar que a cultura literária e a literatura em si são um espaço de criação em que se privilegia a escrita ${ }^{3}$. Por outro lado, essa criação proporcionada por ambas garante uma invenção simultaneamente imaginativa e imagética. Tal fenómeno acontece na medida em que um texto poderá ser entendido enquanto uma trama de conceitos, juízos e raciocínios, por um lado, e por outro percebido como criação de cultura e de leituras sobre a realidade.

A literatura, e cremos que por consequência a cultura literária, através da sua competência criativa promove uma leitura crítico-interpretativa da sociedade, e das coordenadas espácio-temporais em que os dois elementos mais distantes do esquema da comunicação (emissor e receptor) estão embalados. A literatura não só faculta como também promove no indivíduo uma leitura da sociedade numa perspectiva crítica e analítica. Claro está que ela não se circunscreve à função de "espelho de vida": a literatura é um espaço em que se desenvolve a comunicação entre pessoas. Todavia, o verdadeiro facto que possibilita à literatura ser tão criativa é a capacidade de ampliar a imaginação do homem, conseguindo libertá-lo do jugo de uma verdade divina, tantas vezes dogmática e claustrofobizante (pressupondo obediência), e das peias de uma verdade científica que se quer sempre objectiva. Ainda assim, esta capacidade criativa da literatura não se esgota meramente na possibilidade de criar imagens ou realidades; ela é também uma observação crítica do real, porque o fita, porque o recria, porque o traduz. Desta maneira, a literatura é um espaço de criação ao nível imagético - sobretudo com a prática metafórica - e também ao nível da criação crítico-reflexiva sobre o mundo que envolve o indivíduo.

\footnotetext{
${ }^{3}$ Pressupomos com este conceito noções como escrever, ler, comunicar, estilo, argumentar. Todos eles de um modo mais ou menos directo estão relacionados com o conceito mencionado.
} 
Além disso, as potencialidades da cultura literária estão para além de um simples conhecimento literário aglomerado. Acreditamos que a literatura bem como a cultura literária sejam uma verdadeira Weltanschauung, porquanto são um modo peculiar de exegese do contexto e uma criação de interpretação. Se nos podemos socorrer da literatura como cosmovisão - como capacidade de interpretar o que nos rodeia -, isso exige que vejamos nela uma competência analítica singular e original, que a diferencia da ciência ou da filosofia. É nesta senda que vislumbramos o poder interventivo da literatura na sociedade. $O$ homem, através das suas associações, imitações e interpretações literárias, utiliza a literatura para participar activamente no tecido social e na sua dinâmica. Sabemos que o homem é um animal que privilegia o viver em sociedade, sendo naturalmente necessário interferir nela através de meios persuasivos e convincentes. Um dos modos privilegiados para essa acção é a literatura, enquanto técnica e também enquanto arte. Ela, porque não só reflecte a vida e a realidade, mas também porque é a própria vida e a realidade, sempre teve um forte pendor interventivo no mundo político-social. No entanto, nem todos os géneros literários nem todas as classes de textos têm no indivíduo o mesmo efeito; nem todos eles atingem o mesmo grau de persuasão ou de convencimento. Neste âmbito, levam clara dianteira todas aquelas classes de textos que não estão ligadas nem ao género narrativo, nem ao lírico nem ao dramático, mas sim ao argumentativo, do qual faz parte o ensaio. Descendo mais directamente ao particular, é com alguma inevitabilidade que vemos o ensaio como uma "ferramenta literária" de acção social, seja ela de crítica ou de análise. Porém, sabendo que cultura é acção criadora, no ensaio há uma contundente valorização do que se poderá designar por homo agens, isto é aquele homem que age, intervém, critica e cria. É neste sentido que emerge a capacidade literária do homem e a capacidade criadora da Literatura, seja ela imagética, seja ela reflexiva.

Interagir, no contexto literário, poderá pressupor criticar, apontar, criar..., mas passa principalmente pela acção recíproca que um autor literário procura. Como afirmámos, há classes de textos que têm uma performance persuasiva mais intensa do que outras. Se durante o século XIX, a interacção social foi elaborada com maior preponderância pelo romance, a partir do século $\mathrm{XX}$, aquela que maior fortuna adquiriu foi o ensaio, ou classes de textos de laivos ensaísticos. Na verdade, tanto o romance como o ensaio foram as duas grandes classes de textos que dominaram o século XX. Ambas são classes de textos não normativas, o que não implica a imposição de verdades objectivas e universais. A hegemonia do primeiro estará certamente associada ao seu alcance alargado e à explosão e, de certa maneira, à demolição das suas convenções. Já por seu turno, o ensaio vinca a sua influência no século passado não só porque "invade" outras classes de textos, sejam elas literárias ou não (cf. Langlet, 2000: 45), mas também devido ao crescente interesse social que ele proporcionou. Porém, o romance tal como o conhecemos no século XIX foi 
perdendo o seu vigor enquanto classe de textos dominante. Se é uma evidência que a partir do século $X X$ o romance deixou de ser a escrita de uma aventura para passar a ser a aventura de uma escrita, tal como Jean Ricardou sublinhou, já desde as suas origens que o ensaio é precisamente esse tipo de aventura de escrita. Ele é continuamente uma escrita em aventura, em aventura literária e em cultura verdadeiramente literária, que nos faculta uma andança de escrita e de pensamento, e ainda método de abordagem.

Por outro lado, essa aventura de escrita e em escrita, que se não supera o romance pelo menos contamina-o de um modo muito incisivo, é estimulada e propiciada pela utilização não meramente expressiva mas sim cognitiva da metáfora. $\mathrm{O}$ ensaio, sobretudo o literário, caracteriza-se principalmente por uma escrita metafórica, que vai estimulando as digressões, as alusões, roçando por vezes os terrenos da escrita poética. Daqui decorre em concomitância a sua grande vulnerabilidade e efemeridade, na qual não se escusa em debater os problemas culturais em que está inserido.

No entanto, o ensaio além de ter contaminado o romance foi ocupando o seu espaço e estatuto devido a um aspecto bem identificado: se o romance nos permite viver vidas outras que não somente a nossa, o ensaio possibilita-nos intensificar o modo de agir na nossa própria vida, uma vez que busca e reflecte o indivíduo em si. Não se dirige unicamente para o grande público, já que visa o leitor individual, aquele que num dado momento se confronta com o texto e que com ele se digladia para interpretar o mundo e a si próprio. Tudo isto se processa sob o manto da literariedade. Posto isto, o ensaio é um modo-outro de dizer a verdade, literariamente, através de um estilo criativo e espontâneo, mais aliciante e até mesmo mais eficaz do que um estudo científico - tantas vezes frio, impessoal e por isso desumano. É sustentado neste pressuposto que advogamos que não raras vezes um estudo científico, baseado na sua verdade "objectiva e taxativa", não tem tanto impacto na sociedade quanto um ensaio. Apesar de não percorrer os caminhos da verdade objectiva, mas sim os da verosimilhança mutável e particular, o ensaio através da racionalidade argumentativa consegue espoletar a sensibilidade do leitor de um modo muito mais enérgico e convincente. É por esses motivos que esta classe de textos é sempre um ponto de partida, um expediente; não é um resultado de uma análise e não é um estudo sólido e dissertativo.

Além disso, o ensaio espelha-se na concepção de cultura literária porque é um texto simplesmente mais humano, fazendo de um modo deliberado ou inconsciente transparecer esse humanismo na sua literariedade, frequentemente indecisa e oblíqua. O êxito do ensaio, e mormente do ensaio literário, é o facto de ele ser em si não técnica mas uma obra de arte. Como tal, em uníssono com os pensamentos de Nietzsche que fincava o conceito de cultura centrado na arte, porquanto os artistas produzem fins em si próprios e não meios como fazem consecutivamente os cientistas para atingir os seus diversos fins, o ensaio porque se 
sustenta na literatura adquire uma magnitude que um "simples" estudo científico ou tratado não consegue conter. Escorado na literatura, esta classe de textos consegue com outra capacidade ilustrar e representar não só o próprio mundo como também a vida em si, com outra aptidão e outro virtuosismo que nem um ensaio não literário e muito menos um estudo científico conseguiriam expressar. É neste sentido que o ensaio, baseando-se numa cultura literária, supera indelevelmente outro tipo de classes de textos que ao nível pragmático tenha móbiles e pretensões semelhantes. O sucesso do ensaio literário poderá ter como origem o facto de a literatura avançar de e com verdades mais humildes, não definitivas e carregadas de uma densidade subjectiva e simbólica muito acentuada. Claro está que este avançar da literatura se sustenta muito mais em constantes propostas falíveis do que numa progressão linear, típica da ciência ou até mesmo do pensamento sistemático da filosofia.

Relacionando-se com a questão interventiva da literatura, partindo do pressuposto de que muitos dos ensaios têm em si essa literariedade, podemos concluir que ele é utilizado como um instrumento ${ }^{4}$ de acção e de discussão de cultura em cultura. Por outro lado, além de ferramenta, o ensaísmo poderá ser encarado não como sistema, porque a ele é avesso, mas como método estruturante e/ou expediente para uma análise crítica da circunstância que envolve o ensaísta. Não nos esqueçamos que a Literatura é acima de tudo Vida e que o ensaio é uma classe de textos extremamente vital, dado que surge dela, com ela e para ela. Além disso, esse jorro de vida que corre pelas entrelinhas ensaísticas em muito se deve ao facto de o ensaio ser ciência sem prova explícita, o que deixa transparecer a sua competência literário-persuasiva, valendo-se de uma racionalidade argumentativa, em que se escora fortemente na utilização metafórica, que torna a sua capacidade analítica tão acutilante, tão forte e vigorosa. A metáfora é um reservatório pleno de sentido, não tanto porque ela seja uma representação do sentido, mas porque ela é em si a própria construção do sentido. É a criação de um sentido e de uma análise literária.

No entanto, além de o ensaio ser por vezes literário por essência, ele também analisa a própria Literatura, criticando-a ora em termos mais teóricos ora numa perspectiva mais pragmática. Assim sendo, o ensaísmo também pode patrocinar um maior conhecimento da cultura literária, no sentido mais canónico do termo, além de que também incrementa o conhecimento da cultura literária, bem como o seu desenvolvimento. Para tal, vale-se amiudadamente o ensaio da intertextualidade e transtextualidade ${ }^{5}$. Contudo, a sua intertextualidade permite-lhe ser uma classe de textos que vagueia no "entre": entre o

\footnotetext{
4 "O ensaio é um expediente literário para dizer quase tudo sobre quase qualquer coisa." (Huxley, 1960: v)

${ }^{5}$ A contaminação ensaística é também intertextualidade. Todavia, pressupomos que neste âmbito não haja simplesmente intertextualidade (seja endoliterária ou exoliterária (cf. Silva, 1993: 629-630), mas concomitantemente transtextualidade, no sentido proposto por Genette (Genette, 1982: 7). Torna-se, portanto, jussivo perspectivar o ensaio não apenas como um texto do "talvez" ou do "quase", mas também do "entre", pois ininterruptamente as suas fronteiras definitórias se estabelecem em movimento por entre áreas e classes de textos diversas.
} 
literário, entre o científico, entre o filosófico ${ }^{6}$. É um texto de "entretexto", porque expande o seu raio de acção e porque se vale de várias áreas do saber.

O ensaio é uma capacidade literária de observar o mundo. Essa competência devese, em grande medida, a uma "vontade de estilo" que o ensaísta lhe imprime. Contudo, note-se que, embora todo o ensaio tenha em si adjudicado um estilo próprio, tal não é razão sine qua non para the conferirmos literariedade. Na realidade, poderemos adiantar que a "especificidade literária do ensaio surgirá da vontade expressiva do autor, patente no uso pessoal dos recursos linguísticos da sua língua natural e no modo de apresentação e disposição das ideias" (Arenas Cruz, 1997: 131). Assim, estamos certos de que o ensaio é um texto com as potencialidades e características necessárias, para que the possa ser vislumbrada "literariedade" ${ }^{7}$, caso essa seja a aspiração do seu autor. Sufragamos, portanto, no contexto do ensaio as palavras de Guerra de Cal: "o estilo literário vai muito mais além do meramente verbal. Ter estilo não é possuir uma técnica de linguagem, mas ter uma visão própria do mundo, e ter conseguido uma forma adequada para a expressão dessa paisagem interior" (Guerra da Cal, 197?: 26). Conceber o estilo como a manifestação de certa uma atitude, que no contexto do ensaio é com frequência literária, entronca na expressão de algumas concepções que vislumbram o ensaio simplesmente como uma atitude. Eis o que se entende por atitude ensaística.

Abrindo agora um pouco mais o perímetro da discussão, retomando o tópico da valorização de uma observação sob a lente de uma cultura literária, vejamos o que se tem passado na realidade portuguesa. Desde muito cedo houve no quadro da nossa literatura manifestações, cujo pendor se marcava claramente por um espírito interventivo e actuante na sociedade, não faltando autores que desempenharam essa função magistralmente. Iniciando-nos nas cantigas de escárnio e maldizer, que colocavam a nu os vícios ou que atacavam pessoas concretas; passando pela preocupação cronística-fundacional de Fernão Lopes, lembremos os autos Gil Vicente, as apreensões de Sá de Miranda, os sermões inquietantes de Vieira já em terras do Novo Mundo; a passo largo pelo friso cronológico, é com facilidade que esbarramos em autores como Verney e chegamos a homens como Quental, Ortigão e Eça, para depois entrar jubilosamente no século XX com António Sérgio, tendo por remate pensadores como Eduardo Lourenço ou José Gil. Cada um à sua maneira, assenhorando-se da literatura como modo de expressão mas também de interpretação, foi intervindo na sociedade apontando críticas, levantando problemas, questionando matérias. Vejamos, então, o caso específico de autores que no século passado se socorreram do

\footnotetext{
${ }^{6}$ Torna-se, portanto, imperioso perspectivar o ensaio não apenas como um texto do "talvez" ou do "quase", mas também do "entre", pois ininterruptamente as suas fronteiras definitórias se estabelecem em movimento por entre áreas e classes de textos diversas.

${ }^{7}$ Para um necessário conhecimento da amplitude deste conceito, consulte-se a Teoria da Literatura (Silva, 1993: 14-16).
} 
ensaio ou de classes de textos latentes para expressarem as suas ideias, com o objectivo de acicatar o leitor e a circunstância envolvente.

Com uma capacidade de intervenção muito forte e até mesmo preponderante para a mutação do quadro político-social de uma dada época, temos o exemplo flagrante de como um texto pode influenciar a interpretação de um fenómeno. Poderíamos chamar casos canónicos como é por exemplo António Sérgio, que com uma escrita ensaística sui generis e com traços literários marcados vai analisando a cultura portuguesa. Temos também o exemplo de Eduardo Loureço, o filósofo-ensaísta da cultura portuguesa, que através de uma escrita de rendilhado, em que o fio condutor de cada ensaio se assemelha a um fio de algodão sabiamente entrelaçado numa dinâmica de rendilhado, analisa e interpreta a nossa cultura e a nossa sociedade. Artisticamente engendrado, e redigido eivando-se de desígnios literários, o ensaio lourenceano vai progredindo desde o seu título até à última frase com um sentido de "interpretação de compreender", propiciando ao leitor não apenas a curiosidade de quem lê um ensaio, mas também o deleite de quem desfruta de um romance: cativa-o pela ideia que sugere, pelo modo como o afirma, bem como pelos pensamentos que $a$ posteriori lhe proporciona.

Consideremos também o caso de José Gil, que muito foi falado na praça pública devido ao imediatismo que Portugal Hoje - o medo de existir adquiriu. Publicado num contexto bastante particular da sociedade portuguesa, vem chamar a atenção para certos pontos específicos do carácter português, que se tornam dramáticos em momentos de crise. Não sendo pertinente aludir aos argumentos específicos aventados pelo autor, este livro (colectânea de ensaios) teve um considerável impacto ao nível social, maior do que se os argumentos apresentados tivessem sido trazidos por um estudo científico. É a opinião e o seu poder que no ensaio se matizam de literatura para transformar a vida em que participam, tendo no ensaísmo uma função e uma autoridade sociais consideráveis.

Acompanhando as mutações da sociedade e do mundo em que vivemos, o ensaio por ser proteiforme, adapta-se aos suportes e aos modos de publicação que vão surgindo. Vejamos, à guisa de exemplo, o caso da invasão ensaística pelos meandros da blogosfera. Esta nova realidade, trazido pela revolução informática da Internet, desencadeou a eclosão de uma comunidade que elabora, disponibiliza e frequenta os chamados blogues. Um compromisso entre a escrita diarística e o comentário na maior parte das vezes, encontramse não sem já alguma frequência várias intromissões de ensaísmo e de uma preocupação de cultura literária no universo dos blogues. Utilizando os autores os seus blogues como suporte, e adaptando os seus escritos às contingências que eles exigem, o ensaio molda-se às novas exigências. Ainda que a escrita presente nestes blogues não seja verdadeiramente literária, porque não é essa na maior parte dos casos a ambição, estas incursões ensaísticas são uma nova forma de escrita e de diálogo a ter em consideração. 
Veja-se o caso de blogues como o Abrupto ${ }^{8}$ de José Pacheco Pereira, em que o autor também o utiliza para disponibilizar textos marcadamente cronísticos ou ensaísticos que publica noutros suportes - nomeadamente periódicos. Temos também o caso do Causa nossa, blogue com oito autores ${ }^{9}$, em que se discute em pequenos apontamentos, ou em textos mais extensos, os assuntos - normalmente político - mais marcantes da actualidade. Não obstante, existem também na blogosfera casos que buscam inequivocamente ora o comentário literário, ora a cultura literária, ora ainda a criação literária mais pura. Vejamos alguns exemplos, que não pretendem ser paradigmas, mas unicamente exemplos da miríade de realidades que poderão aparecer. Unicamente para agilizar a análise, faremos algumas segmentações para que seja mais fácil visionar as diferentes incursões não apenas do ensaio mas também da literatura na blogosfera ${ }^{10}$.

Interessar-nos-emos não por blogues de fundações ou instituições, nem por blogues de revistas relacionadas com Literatura ou Cultura, nem ainda por blogues de editoras ou livrarias. O nosso escopo recai essencialmente naqueles casos em que autores conhecidos ligados ao mundo cultural ou literário (sejam eles autores ou críticos) e também nos blogues em que se realiza produção literária mais intensivamente (seja ela ou não ensaística). Comecemos pelo primeiro grupo. Sem fazer uma listagem exaustiva, dado que tal seria uma empresa quase impossível, daremos conta de alguns dos exemplos que ressaltam na blogosfera portuguesa. Perspectivemos os casos de blogues como o Da Literatura, o Origem das Espécies, o Bibliotecário de Babel, o Literatura e Arte, e ainda o Ciberescritas ${ }^{11}$. A primeira impressão que estes blogues nos suscitam é a particularidade dos seus títulos.

\footnotetext{
${ }^{8}$ Nota bene: todos os comentários sobre os sítios da Internet consultados, nomeadamente os blogues, têm em consideração a sua fisionomia e lógica de conteúdo que apresentavam na altura da realização deste estudo.

${ }_{9}$ Ana Gomes, Jorge Wemans, Luís Filipe Borges, Luís Nazaré, Luís Osório, Ma. Manuel Leitão Marques, Vicente Jorge Silva, Vital Moreira.

${ }^{10}$ Neste âmbito, não centraremos a nossa atenção em blogues que falam sobre literatura ou do mundo a ela ligado, mas sim dos blogues que escrevem sobre literatura de um modo ensaístico, ou dos blogues que escrevem em literatura. Assim sendo, noticiamos apenas alguns que no primeiro grupo se inserem. Muitas das fundações e outras instituições que promovem o estudo de certos autores optaram por divulgarem as suas actividades e/ou conteúdos através do conceito blogue. Dessa realidade participam a Fundação José Saramago e a Casa Fernando Pessoa (Blogue da Fundação José Saramago (<URL: http://blog.josesaramago.org/>); $O$ Blogue da Casa Fernando Pessoa com Notícias de Poesia e Literatura (<URL: http://mundopessoa.blogs.sapo.pt/>). Nestes espaços, publicitam-se iniciativas e eventos e dão-se a conhecer temáticas relacionadas com o mundo literário. Não há a pretensão de escrever literariamente. Há também neste espaço algumas livrarias e editoras que marcam presença neste espaço, não só para dar a conhecer às sua novidades, mas também para publicitarem alguns dos eventos ao nível literário e cultural, que vão sendo por si dinamizados (veja-se o caso da livraria Pó dos Livros (<URL: http://livrariapodoslivros.blogspot.com/>) e da editora Assírio \& Alvim (<URL: http://www.assirioealvim.blogspot.com/>). Paralelamente com o agrupado anterior veja-se 0 caso de algumas revistas também do foro literário e cultural. A revista Ler $(<U R L$ : http://ler.blogs.sapo.pt/>) e o ressurgimento da antiga revista A Águia, agora com o título Nova Águia: revista de cultura para o século XXI (Nova Águia: o blogue da Lusofonia (<URL: http://novaaguia.blogspot.com/>)), são dois bons casos sobretudo pela diferença que deles advém de blogues que carimbam uma posição na cultura em Portugal ao nível literário.

${ }^{11}$ Da Literatura (<URL: http://daliteratura.blogspot.com/>) de Eduardo Pitta e João Paulo Sousa; Origem das Espécies (<URL: http://origemdasespecies.blogs.sapo.pt/>) de Francisco José Viegas; Bibliotecário de Babel (<URL: http://bibliotecariodebabel.com/>) de José Mário Silva; Literatura e Arte (<URL: http://literaturaearte.blogspot.com/>) de Yvette Centeno; Ciberescritas (<URL: http://www.ciberescritas.com/>) de Isabel Coutinho.
} 
Grosso modo, independentemente do motivo que impulsionou os autores a assim os construírem, estes títulos estão marcados com a carga do campo semântico da literatura. À partida, sugere-se a área por onde se andará, marcam-se os temas que preferencialmente serão abordados. No entanto, ainda que estejamos perante autores ligados de um modo mais ou menos directo ao panorama crítico-literário, não se escusam de opinar sobre outras matérias que numa dada altura entendam como pertinente. A par da crítica literária mais técnica, temos o comentário fortuito, muito em jeito de ensaio. Cada um destes escritores de blogues, à sua maneira, dá a conhecer livros, eventos; noticia a sua opinião sobre um dado assunto cuja ligação directa com a literatura poderá ser menos visível.

Há ainda blogues que se dedicam exclusivamente à produção literária, optando por se escrever pequenos textos que se poderão enquadrar em vários géneros literários. Neste apartado se enquadra J. Rentes de Carvalho ${ }^{12}$. No Tempo Contado, o seu autor amiúde em colorações intimistas vai contando, discorrendo sobre o tempo que (por si) passa. É uma interessante concepção de blogue, uma vez que afastando-se de uma certa noção canónica se embrenha por uma escrita entusiasmante, fluida e atractiva. Neste caso, há apontamentos ensaísticos, se bem que não são esses os traços dominantes na escrita do autor. O que se nota com mais veemência é um escrever marcadamente literário. Temos também o caso de Poesia Portuguesa: dedicado a todos os que gostam dela ${ }^{13}$, que se sustenta como suporte de publicação de textos de vários autores, ou então como a recuperação de textos de autores consagrados. Coadunando imagem com texto, este blogue conjuga pintura com literatura; os textos vão evoluindo entre a poesia e a prosa poética, sempre com o intuito de expressão artística e de sentimento.

Como poderemos observar, é quase impossível traçar um fio condutor, por entre a miríade de possibilidades bloguísticas, que talhe e classifique o modo como a Literatura tem estado presente neste universo. Temos sim a certeza de que as possibilidades são imensas e sobretudo diversas, o que corrobora a grande plasticidade e potencialidade de adaptação que o mundo literário tem, face às novas exigências e aos novos padrões de escrita que as tecnologias vão criando. Assim sendo, há ainda na Tecnologia espaço que permite a criação de Arte, deixando-se emaranhar tranquilamente pelas frestas da escrita. Por outro lado, vemos também que a blogosfera veio trazer novas formas de discussão e modos de exercer a cidadania que até aqui eram impossíveis. Ainda que nem sempre sob o véu da literatura mais canónica, sabemos que é certamente numa óptica de cultura literária que se vai debatendo assuntos e escrevendo sobre o contexto que vai rodeando cada autor. Neste particular, se não o ensaio, pelo menos a escrita ensaística exerce aqui uma função

\footnotetext{
12 Tempo Contado (<URL: http://www.tempocontado.blogspot.com/>).

${ }^{13}$ Poesia Portuguesa: dedicado a todos os que gostam dela (<URL: http://portuguesapoesia.blogspot.com/>).
} 
essencial, adaptando-se às contingências da blogosfera, com o objectivo de criticar e analisar dubitativamente.

Em jeito de epítome, deambulámos ao longo deste estudo pela sinuosidade da cultura literária que o ensaio nos confere. Sabemos que esta classe de texto é motor de polémica social, visando uma acção efectiva - por isso é uma mais-valia o facto de o ensaio ter uma perspectiva tripartida da realidade: Ciência, Filosofia e Literatura em osmose permitem-Ihe artisticamente interferir e intervir na realidade humana. De um modo geral, podemos considerar que o ensaio vai oferecendo uma leitura e uma análise literárias da sociedade. Na esteira do pensamento de Rorty, a literatura dá-nos uma verdade - seja ela instavelmente tranquilizante, seja ela calmamente inquietante. Cabe ao ensaio, pela capacidade envolvente que devém da literatura, mas também pela subjectividade que the trespassa as veias, estimular os leitores, seduzindo-os simultaneamente ${ }^{14}$. Na senda de Eduardo Lourenço, a tal experimentação do possível, que reiteradamente o ensaio garante, vem pincelada com traços de literariedade. Por isso, ele vai explorando os possíveis que a literatura nos concede, analisando a cultura com a paciência crítica que cada "talvez" tem para dar.

Esta classe de textos, no âmbito da cultura literária, é uma literacia de vida, permitindo interpretá-la e modificá-la. Se cultura literária é a humana exploração da realidade, o seu cultivo, que paulatinamente tende a superar a religião e a filosofia, embora delas se sirva, promove uma verdadeira interacção do homem consigo mesmo - porque com o Outro, porque com o Eu. Através de um texto, de uma pintura, de uma melodia ou até mesmo de uma cidade, a cultura literária oferece a cada um individualmente outras possibilidades de se ser humano. Essa nova capacidade advém da relação interpretativa com o outro, mas também com os elementos físicos que nos rodeiam. Desta feita, a cultura literária tendo a capacidade de imaginar e criar novos mundos tem ferramentas que aclaram de um outro prisma o mundo em que nos inserimos e vivemos.

\footnotetext{
${ }^{14}$ O ensaio é certamente um expediente de comunicação que pelas suas características formais é um recurso ajustado para poder criticar a cultura de um modo avalisado e sustentado. Claro está que esta visão interpretativa da cultura parte sempre da leitura muito própria do ensaísta. $O$ ensaio vai-se construindo devido ao comércio nem sempre pacífico entre os vectores: por um lado, "o de pensar e descrever a realidade e as formações culturais tal como são em si mesmas e [por outro lado] o de impor necessariamente um ponto de vista sobre elas. A consequência é a impossibilidade de objectividade" (Arenas Cruz, 1997: 129).
} 


\section{Bibliografia}

AssíRIO \& ALVIM, "Assírio \& Alvim" [blog] <URL: http://www.assirioealvim.blogspot.com/>.

ARENAS CRUZ, Maria Elena (1997). Hacía una teoría general del ensayo. Construcción del texto ensayístico. Cuenca: Univ. de Castilla - La Mancha.

BLOGUE DA FUNDAÇÃO JOSÉ SARAMAGO [blog] <URL http://blog.josesaramago.org/>.

BORGES, Paulo, NATÁRIO, Celeste, EPIFÂNIO, Renato, "Nova Águia: revista de cultura para o século XXI (Nova Águia: o blogue da Lusofonia)" [blog] <URL: http://novaaguia.blogspot.com/>.

CARVAlHo, J. Rentes de, "Tempo Contado" [blog] <URL: http://www.tempocontado.blogspot.com/>.

Casa Pessoa, 'Mundo Pessoa, o Blogue da Casa Fernando Pessoa com Notícias de Poesia e Literatura" [blog] <URL: http://mundopessoa.blogs.sapo.pt/>.

CENTENO, Yvette, "Literatura e Arte" [blog] <URL: http://literaturaearte.blogspot.com/>.

GIL, José (2005). Portugal, hoje: o medo de existir. Lisboa: Relógio de Água.

GOMES, Ana, WEMANS, Jorge, BORGES, Luís Filipe, NAZARÉ, Luís, OSÓRIO, Luís, MARQUES, Ma․ Manuel Leitão, SILVA; Vicente Jorge, MOREIRA, Vital, "Causa Nostra" [blog] <URL: http://causanossa.blogspot.com/>.

COUTINHO, Isabel, "Ciberescritas" [blog] <URL: http://www.ciberescritas.com/>.

GeneTte, Gérard (1982). Palimpsestes. La Littérature au second degré. Paris: Seuil.

LOURENÇO, Eduardo (1982). Labirinto da Saudade. Lisboa: Gradiva.

GueRRA DA CAL, Ernesto (197?). Linguagem e estilo de Eça de Queiroz. Lisboa: Editorial Aster.

HuXLEY, Aldous (1960). Preface. Collected Essays, New York: Bantam Books.

LANGLET, Irène (2000). "Théories du roman et théories de l'essai au XX $X^{e}$ siècle". In: Philippe, Gilles (dir.), Récits de la pensée: Études sur le roman et l'essai. Paris: Sedes/HER.

MATIAS, André (2008). "Pascoaes e Sérgio ou «o rouxinol e o peixe» - polémicas e tensões ensaísticas n'A Águia". In: Barker, Anthony (coor.), Giving and Taking Offence - Ofender e ser ofendido. Aveiro: Universidade de Aveiro.

LER, "Ler" [blog] <URL: http://ler.blogs.sapo.pt/>.

"Poesia Portuguesa: dedicado a todos os que gostam dela" [blog] $<U R L$ : http://portuguesapoesia.blogspot.com/>.

PEREIRA, José Pacheco, "Abrupto" [blog] <URL: http://abrupto.blogspot.com/>.

PITTA, Eduardo, SOUSA, João Paulo, "Da Literatura" [blog] <URL: http://daliteratura.blogspot.com/>.

Pó dos LIVROS, "Pó dos Livros" [blog] <URL: http://livrariapodoslivros.blogspot.com/>.

SILVA, José Mário, "Bibliotecário de Babel" [blog] <URL: http://bibliotecariodebabel.com/>.

SILVA, Vítor Manuel Aguiar e (1993). Teoria da Literatura. Coimbra: Livraria Almedina.

VIEGAS, Francisco José, "Origem das Espécies" [blog] <URL: http://origemdasespecies.blogs.sapo.pt/>.

ZAmBrano, María (2004). Unamuno. Barcelona: Debolsillo. 